\title{
A bi-proxy reconstruction of Fontainebleau (France) growing season temperature from A.D. 1596 to 2000
}

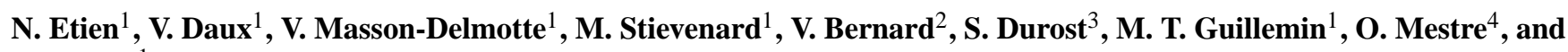 \\ M. Pierre ${ }^{1}$ \\ ${ }^{1}$ Laboratoire des Sciences du Climat et de l'Environnement (IPSL, UMR CEA-CNRS 1572) L'Orme des Merisiers, Bâtiment \\ 701, CEA Saclay, 91191 Gif-Sur-Yvette cedex, France \\ ${ }^{2}$ Dendrochronologie et Archéo-dendrologie (UMR 6566 "Civilisations Atlantiques et Archéosciences") Université de Rennes \\ 1, Campus de Beaulieu, Bât 24/25, 35042 Rennes, France \\ ${ }^{3}$ Laboratoire de Chrono-Ecologie (UMR 6565), Université de Franche-Comté, UFR des Sciences, La Bouloie, 16 route de \\ Gray, 25030 Besançon, France \\ ${ }^{4}$ Météo France, Direction de la climatologie, 42 avenue Gaspard-Coriolis, 31057 Toulouse Cedex, France
}

Received: 18 September 2007 - Published in Clim. Past Discuss.: 11 Ocotober 2007

Revised: 7 May 2008 - Accepted: 11 May 2008 - Published: 27 May 2008

\begin{abstract}
In this paper, we develop a new methodology to estimate past changes of growing season temperature at Fontainebleau (northern France). Northern France temperature fluctuations have been documented by homogenised instrumental temperature records (at most 140 year long) and by grape harvest dates (GHD) series, incorporated in some of the European-scale temperature reconstructions. We have produced here three new proxy records: $\delta^{18} \mathrm{O}$ and $\delta^{13} \mathrm{C}$ of latewood cellulose of living trees and timbers from Fontainebleau Forest and Castle, together with ring widths of the same samples. $\delta^{13} \mathrm{C}$ data appear to be influenced by tree and age effects; ring widths are not controlled by a single climate parameter. By contrast, $\delta^{18} \mathrm{O}$ and Burgundy GHD series exhibit strong links with Fontainebleau growing season maximum temperature. Each of these records can also be influenced by other factors such as vine growing practices, local insolation, or moisture availability. In order to reduce the influence of these potential biases, we have used a linear combination of the two records to reconstruct interannual fluctuations of Fontainebleau growing season temperature from 1596 to 2000. Over the instrumental period, the reconstruction is well correlated with the temperature data $\left(R^{2}=0.60\right)$.

This reconstruction is associated with an uncertainty of $\sim 1.1^{\circ} \mathrm{C}$ (1.5 standard deviation), and is expected to provide a reference series for the variability of growing season maxi-
\end{abstract}

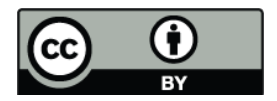

Correspondence to: N. Etien (nathalie.etien@cea.fr) mum temperature in Western Europe. Spectral analyses conducted on the reconstruction clearly evidence (i) the interest of combining the two proxy records in order to improve the power spectrum of the reconstructed versus observed temperature, (ii) changes in the spectral properties over the time, with varying weights of periodicities ranging between $\sim 6$ and $\sim 25$ years. Available reconstructions of regional growing season temperature fluctuations get increasingly divergent at the interannual or decadal scale prior to 1800 . Our reconstruction suggests a warm interval in the late 17th century, with the 1680 s as warm as the 1940 s, followed by a prolonged cool period from the 1690 s to the 1850 s culminating in the 1770s. The persistency of the late 20th century warming trend appears unprecedented.

\section{Introduction}

Documenting the climate natural variability is important to characterise the modes of this variability and the response to natural forcing, to evaluate the relevance of the variability simulated by climate models, and to identify anthropogenic effects (IPCC, 2007).

At the European scale, several attempts have been made to quantify temperature changes during the past centuries (Briffa et al., 2002; Chuine et al., 2004; Luterbacher et al., 2004, 2007; Xoplaki et al., 2005; Guiot et al., 2005; Büntgen et al., 2006; Meier et al., 2007). These Europeanscale reconstructions are mainly based on early instrumental records, high latitude or altitude tree-ring growth indices,

Published by Copernicus Publications on behalf of the European Geosciences Union. 


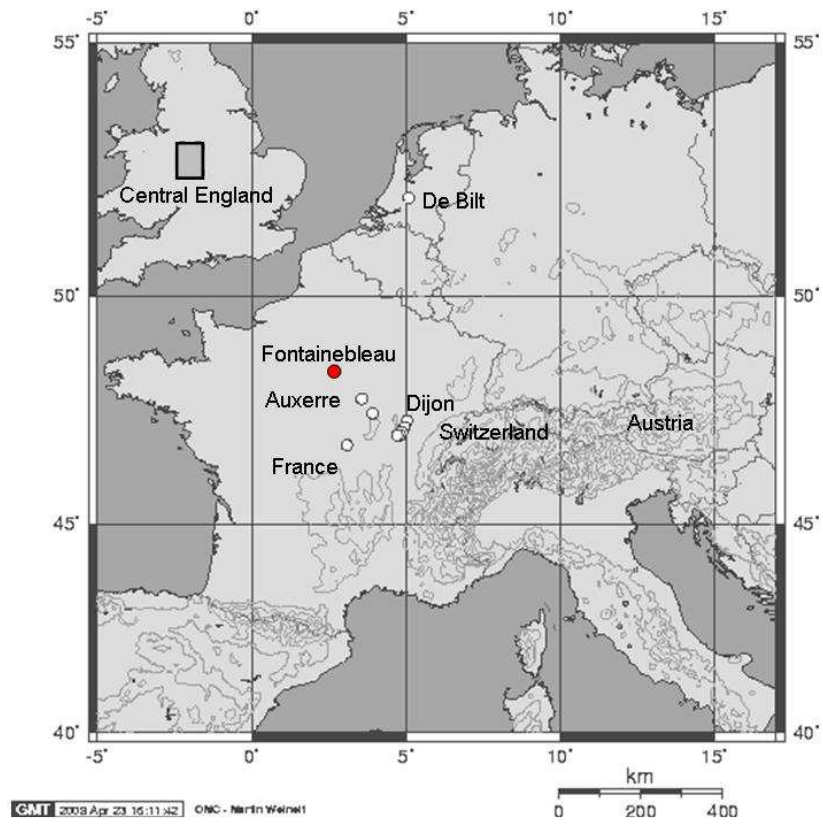

Fig. 1. Location of the Fontainebleau sampling site, of Burgundy grape harvest sites (including Auxerre and Dijon cities) and ancient instrumental record sites of De Bilt (Netherlands) and "Central England" (UK) area as defined by Manley (1974) $\left(52^{\circ} 30^{\prime} \mathrm{N}\right.$ to $53^{\circ} \mathrm{N}$ and $1^{\circ} 45^{\prime} \mathrm{W}$ to $2^{\circ} 15^{\prime} \mathrm{W}$ ). The data used by Büntgen et al. (2006) and Meier et al. (2007) come from Switzerland and Austria. Map by: http://www.aquarius.geomar.de.

and, sometimes, documentary evidences. The spatial coverage of proxy records is important due to specific regional signatures of extreme events such as the 2003 extreme heat wave (Beniston, 2004). However, in these quantitative reconstructions of recent temperature variations, only scarce information from the temperate climate area of northern France is included.

Owing to their annual resolution, tree-ring proxy records are essential for documenting recent climate variability. In high latitude or high elevation, tree-rings widths and maximum densities are sensitive mainly to summer temperature and can therefore provide reliable reconstructions of this parameter (e.g. in Europe: Briffa, 2002; Frank and Esper, 2005; Guiot et al., 2005; Büntgen et al., 2005, 2006). At the contrary, in low elevation temperate areas, tree growth is affected by several factors. For instance, ring-widths were shown to be also controlled by drought for Quercus sp. (Briffa, 2000 ) and by precipitation for Fagus sylvatica (Dittmar et al., 2003). Moreover, ring width and maximum densities are affected by juvenile effect. Detrending methods are used to correct this age effect, but some of these approaches hinder the detection of the centennial to multi-centennial variability (Briffa et al., 2001). Recent statistical methods have been developed in order to best preserve the low frequency variability of dendrochronological records (Esper et al., 2002).
Other methods are being developed in order to combine low and high frequency records at hemispheric (Moberg et al., 2005) or regional scale (Guiot et al., 1983).

The oxygen isotope composition of ring wood cellulose has been shown to be sensitive to changes in climate and water stress in temperate areas (see McCarroll and Loader, 2004 for a review), and to provide annually resolved growing season temperature records with limited age-related growth trends (amongst recent publications: Anderson et al., 2002; Robertson et al., 2001; Saurer et al., 2002; Raffali-Delerce et al., 2004; Danis et al., 2006; Etien et al., in press). It is, therefore, a powerful alternative to tree-ring width proxy for temperature reconstruction in temperate area. However, the relationship between $\delta^{18} \mathrm{O}$ and the growing season temperature may be distorted through time due to changes in moisture origin (affecting precipitation $\delta^{18} \mathrm{O}$ ), precipitation seasonality (affecting soil water $\delta^{18} \mathrm{O}$ ) and leaf water enrichment processes.

In temperate areas, grape harvest dates (GHD) series are another annually resolved proxy for spring-summer air temperature. GHD are influenced by the socio-economical context in which grape picking takes place, and are, as such, possibly biased estimations of the phenological maturity. The uncertainty of the GHD values, to our knowledge, has never been estimated. Long documentary Burgundy GHD records (Chuine et al., 2004) are the single source of information regarding past temperature variations in northern France prior to the instrumental period.

In the present research paper, we focus on the poorly documented temperate area of northern France. Here, we add a new temperature-sensitive proxy record, using stable isotope measurements conducted on tree rings. We first present the variation of the $\delta^{18} \mathrm{O}$ and $\delta^{13} \mathrm{C}$ in the cellulose of oak-trees at Fontainebleau (northern France) from 1596 to 2000. A preliminary study (Etien et al., in press) has shown that $\delta^{18} \mathrm{O}$ in the cellulose of Fontainebleau oak-trees and Burgundy GHD are both correlated with the April to September mean value of maximum temperatures at Fontainebleau ( $T_{\max }$ AMJJAS). As the relationship between growing season temperature and each proxy record $\left(\delta^{18} \mathrm{O}\right.$ and GHD) may be distorted by different types of biases over time, such as those related with vine growing practice, insolation and/or moisture availability (Treydte et al., 2007), we propose a bi-proxy linear model which takes advantage of these two independent datasets and improves the quality of the temperature reconstruction and its spectral properties. We finally compare this new reconstruction of the variation of the growing season temperature in northern France with other available estimates of the evolution of Western Europe temperature over the past centuries. 


\section{Material and method}

The study is focused on the Fontainebleau area, northern France $\left(2.67^{\circ} \mathrm{E}, 48.38^{\circ} \mathrm{N}\right)$ (Fig. 1). This region was selected for the availability at the same place 1) of forest trees and timber wood from ancient buildings for isotopic analyses, 2) of documentary information and 3) of homogenised meteorological records.

Fontainebleau has a typical temperate oceanic climate with regular year-round distribution of precipitation (between 50 and $70 \mathrm{~mm} /$ month). The yearly amplitude of monthly maximum temperature is $20^{\circ} \mathrm{C}$. Today, the Fontainebleau forest covers a $280 \mathrm{~km}^{2}$ area and culminates at $144 \mathrm{~m}$ above sea level. Stampian limestones form the substrates and oak roots develop in a loamy soil.

The first subsection describes the tree and timber wood sampling, the pooling strategy to obtain enough material for isotopic analyses, the analytical procedure and the inter-site isotopic dispersion. The second subsection is focused on the construction of the Burgundy GHD record using documentary data, as well as an assessment of the uncertainty linked with GHD. Finally, the methodology used to reconstruct past growing season temperatures using cellulose $\delta^{18} \mathrm{O}$ and GHD is described together with an uncertainty calculation.

\subsection{Sampling and isotopic analyses}

Fieldwork was achieved with the support of "Office National des Forêts" and the "Conservation du Musée-Château de Fontainebleau". In Fontainebleau forest, 15 dominant oaktrees were sampled in year 2000 ( 3 cores at $120^{\circ}$ per tree at $1.30 \mathrm{~m}$ height). This sampling covers the time period from 1829 to 2000 . For older periods, we sampled timbers from historical buildings in the castle of Fontainebleau: 5 timbers from "salle des Bals" (ballroom) and "Clocher" (steeple), 9 timbers from "Théâtre" (theatre) and 4 timbers from "Petites Ecuries" (little stables). The building wood was assumed to originate from forests of the neighbourhood.

Living oak tree rings were cross-dated by the Phytoecology team of INRA Nancy. Dating relies on a master series constructed with more than 400 oaks from Fontainebleau Forest (Etien et al., in press). The dating of beam wood samples of the "Château de Fontainebleau" was conducted in collaboration with dendrochronology laboratories from the University of Rennes (V. Bernard) and Besançon (S. Durost). The quality of the cross-correlation was assessed using the methodology of Baillie and Pilcher (1973). The total number of latewood rings available for a given year varies between 2 and 18, with an average of 7 samples prior to 1829 . The ring widths of each tree or timber wood sample are displayed in the supplementary material http://www.clim-past. net/4/91/2008/cp-4-91-2008-supplement.pdf of this paper. Altogether, our tree samples come from 5 different "populations", reflecting the different periods of Fontainebleau castle construction; they have only little overlap around 1750 and
1840 (see supplementary information http://www.clim-past. net/4/91/2008/cp-4-91-2008-supplement.pdf).

Each ring was cut with a scalpel under a binocular magnifier to separate late wood from early wood. We discarded the early wood because it is elaborated from carbohydrates stored from previous years (Barbaroux and Bréda, 2002). Samples were milled with a $0.08 \mathrm{~mm}$ sieve in order to homogenise the material. $\alpha$-cellulose was extracted from wood according to the SOXHLET method elaborated by Green (1963) and modified by Leavitt and Danzer (1993). The isotopic composition were determined with a Carbo Erba ${ }^{\circledR}$ elemental analyser coupled to a Finnigan MAT252 mass spectrometer (at LSCE, Gif/Yvette, Fr) according to the procedure described in Raffalli-Delerce et al. (2004). The measured sample values were corrected from an internal laboratory reference of cellulose (Whatmann® ${ }^{\circledR}$ CC 31 ) which had been inter-compared by the European laboratories involved in the ISONET European project (Boettger et al., 2007). Repeated analysis of the oxygen and carbon isotope composition of CC31 yielded standard deviations of $\pm 0.25 \%$ and $\pm 0.10 \%$ o respectively.

Latewood tree-rings formed in the same calendar year were pooled together. In contrast with the large number of tree samples required to build dendrochronological master series, a short number of samples is appropriate to produce a regional $\delta^{18} \mathrm{O}$ signal. Etien et al. (in press) have shown, indeed, that owing to a great inter-tree coherency, the pooling of only three oaks latewood was enough to generate a consistent and reproducible signal. Here, the number of trees (or beams) pooled to set up a sample was superior to 3 except between 1596 and 1610 and between 1733 and 1759. Due to the lack of material, some years were not represented in the record $(1716,1724,1725,1735,1736,1744$ to 1747,1848 , $1905,1909,1934,1963,1965$ and 1970). For the reconstruction (see Sect. 3), missing data were replaced by the average of the 2 previous and 2 following years.

To test the inter-site signal coherency, we compared the 6-year-long records (1844-1850, 1848 excepted) measured on "Théâtre" and living trees samples (Fig. 2a). The short length of the test period is constrained by the availability of material. The mean value of $\delta^{18} \mathrm{O}$ signal for this overlap period is $31.26 \%$ o for beams of "Théâtre" site and 30.80\%o for living trees. This $0.46 \%$ difference is of the same order as the maximum inter-site difference measured between different groups of living oaks at Fontainebleau ( 0.54 ; Etien et al., in press) and other sites in France (MassonDelmotte et al., 2005; Danis et al., 2006). Ideally, a test should be made on a longer overlap period. However, despite our diligent searches we were not able to find older living trees or more recent beams to expand the overlap. Hereafter, for the overlap period, the mean value of the two signals is considered. Similar inter-tree analyses conducted on longer time intervals (Fig. 2a) have revealed a much larger dispersion of $\delta^{13} \mathrm{C}$ raw data (Fig. 2a, and "supplementary information http://www.clim-past.net/4/91/ 

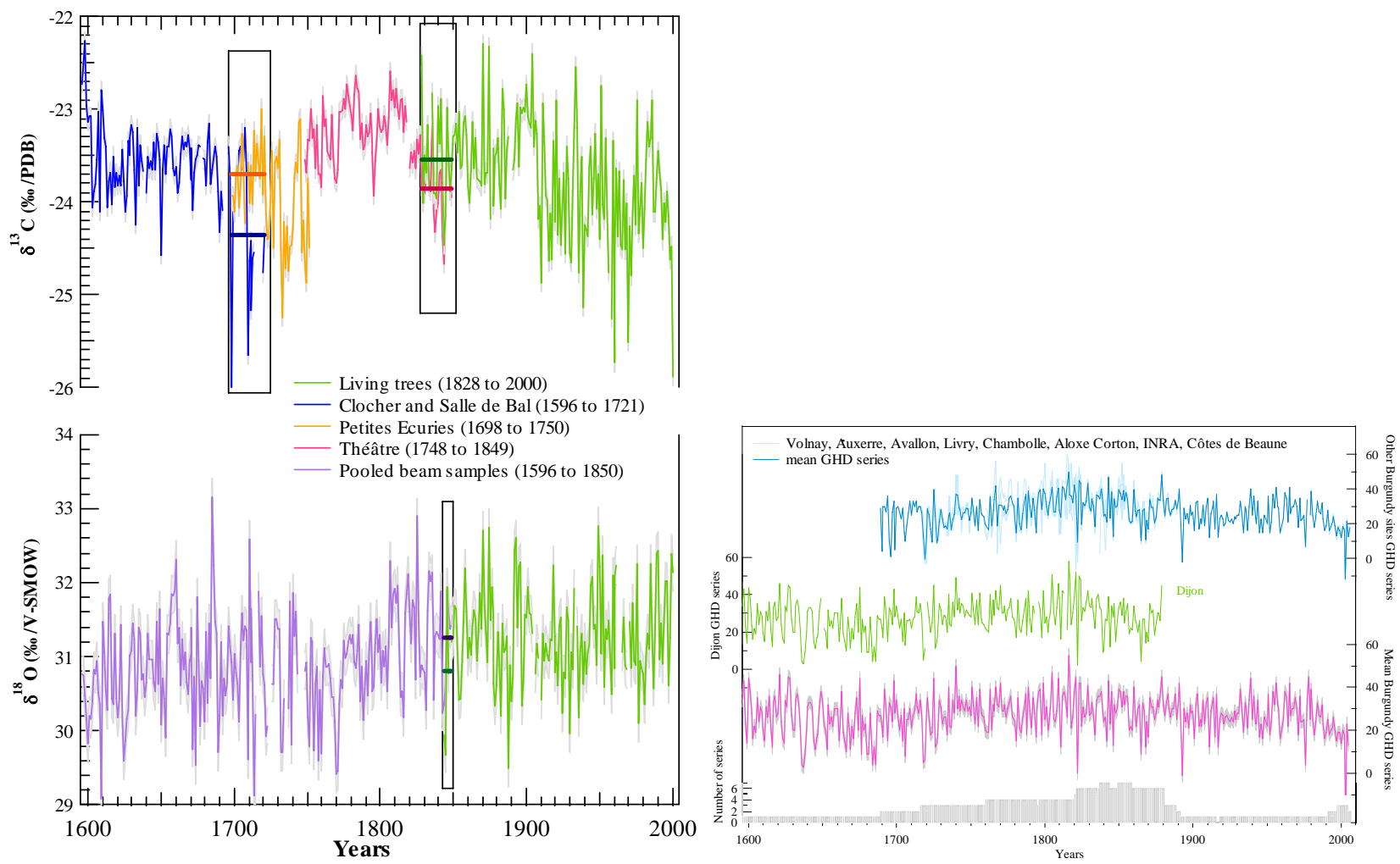

Fig. 2. Proxy records and inter-site dispersion.

(a) Records of tree ring cellulose isotopic composition $\left(\delta^{13} \mathrm{C}\right.$ and $\delta^{18} \mathrm{O}$, in ) measured over pooled samples. The analytical uncertainty ( \pm 0.1 and $\pm 0.25 \%$ for $\delta^{13} \mathrm{C}$ and $\delta^{18} \mathrm{O}$ respectively) is displayed with grey shadowing. Rectangles are used to show the overlap periods between different sampling sites; the horizontal marks in these boxes correspond to the mean value of each isotopic series for these overlap periods. $\delta^{13} \mathrm{C}$ measurements were conducted on each year and for the contoured periods site by site. Due to the lack of material (too narrow rings), it was not possible to measure $\delta^{18} \mathrm{O}$ for some years (see text, Sect. 2.1) and for each site. This is why a single and short overlap segment is available for this proxy.

(b) Local series of Burgundy GHD used to build the stacked Burgundy series: Dijon series (the longest Burgundy series) (green); average of all other sites (blue) and stacked Burgundy GHD series (Chuine et al., 2004, and Le Roy Ladurie, personal communication for 1978). This record is constructed as the median of the local series shown above. The error shown by the grey shading is calculated using the maximum standard deviation between local series (3 days). Number of local series used to establish the Burgundy GHD (grey shaded area).

2008/cp-4-91-2008-supplement.pdf'). This argument acts against the use of $\delta^{13} \mathrm{C}$ measurements for long-term temperature reconstructions, despite the fact that it can slightly improve the temperature reconstructions for the 20th century (Etien et al., in press).

\subsection{Grape harvest data}

Vine development annual cycle strongly depends on climate conditions. GHD are influenced by the temperature from March/April to August/September, earlier harvest dates occurring during years with high spring and summer temperatures (Le Roy Ladurie et al., 2006). The harvest dates of "Pinot Noir" grapes in Burgundy (eastern France, $\sim 250 \mathrm{~km}$ south east of Fontainebleau) were shown to be a proxy for the maximum air temperature from April to September $\left(R^{2}=0.50, p<10^{-11}\right)$ (Etien et al., in press). The large spa- tial coherency of temperature in Northern France (as shown for instance in Etien et al., in press) justify the use of Burgundy data in temperature reconstruction at Fontainebleau.

The stacked Burgundy series was constructed from an ensemble of incomplete harvest dates series published in registers of 16 cities or villages in Burgundy (Fig. 2b). For periods where several documentary sources are available, the Burgundy GHD is obtained by using the median of all available local dates. Dates are expressed as a delay with regard to 31 August (Le Roy Ladurie et al., 2006). This Burgundy series is available since the late 16th century without missing data (Chuine et al., 2004 and Le Roy Ladurie, pers. comm. for 1978). It is quite coherent with grape harvest dates from Switzerland (Meier et al., 2007) $\left(R^{2}=0.47\right.$, $n=448, p<0.001$, between Burgundy and Swiss GHD, from year 1599 to 2003), as expected from the spatial coherency of summer temperatures in Western Europe. 
The uncertainty on GHD is here estimated for the first time by calculating the inter-site yearly standard deviation. This deviation is at most 3 days (Fig. 2b). Another source of uncertainty arises from anthropogenic, non climatic effects (Daux et al., in press). This source of uncertainty is extremely difficult to quantify and could introduce artefacts at the decadal or multi-decadal time scales.

\subsection{Calibration methodology and uncertainties}

Over the 20th century, we have tested the linear relationships between the different available proxy records $\left(\delta^{13} \mathrm{C}\right.$, $\delta^{18} \mathrm{O}$, tree-ring growth indices of Fontainebleau forest oaks; Burgundy GHD) and Fontainebleau meteorological data (monthly precipitation, minimum and maximum temperature, relative humidity, hydrological parameters, global radiation, and different combination of successive monthly data) (Etien et al., in press). This statistical analysis highlighted $T_{\max }$ AMJJAS as the key climate variable which exhibits the most robust correlation with tree ring $\delta^{18} \mathrm{O}$ $\left(R^{2}=0.33, n=94, p=1.3 .10^{-9}\right)$ and GHD $\left(R^{2}=0.50, n=97\right.$, $\left.p=7 \cdot 2 \cdot 10^{-16}\right)$. These two proxy records are themselves slightly correlated $\left(R^{2}=0.09, n=91, p=0.004\right)$. Instrumental records of $T_{\max }$ AMJJAS show a large spatial coherency in northern France (Etien et al., in press), justifying the combined use of Fontainebleau and Burgundy proxy data $\left(R^{2}>0.64\right.$ for the sites within the area from $45^{\circ} \mathrm{N}, 2^{\circ} \mathrm{W}$ to $52^{\circ} \mathrm{N}, 7^{\circ} \mathrm{E}$ ). Note that growth indices from our sampled trees or from master chronologies (regional scale) show no strong relationship with a single climate parameter (Etien et al., in press), and that $\delta^{13} \mathrm{C}$ data raise several problems: (i) correction for trends linked with anthropogenic carbon dioxide emissions; (ii) auto-correlation; (iii) strong inter-site variations and links with the number of beam samples (therefore reflecting strong inter-tree variability) (see supplementary information http://www.clim-past. net/4/91/2008/cp-4-91-2008-supplement.pdf); (iv) potential trends linked with the age of the trees (e.g. Raffalli-Delerce et al., 2004). Therefore, tree growth indices and $\delta^{13} \mathrm{C}$ were not considered for past temperature reconstruction.

In a second step, a multiple linear regression analysis was conducted in order to build the best linear combination of $\delta^{18} \mathrm{O}$ and GHD data with $T_{\max }$ AMJJAS as a reconstruction target. The best correlation was obtained using all the dataset (1900 to 2000). The regression equation is as follows:

$$
\begin{aligned}
& \Delta T_{\max } \mathrm{AMJJAS}=0.76 \pm 0.13 \times \Delta \delta^{18} \mathrm{O}--0.09 \pm 0.01 \\
& \times \Delta \mathrm{GHD}\left(R^{2}=0.60, n=91, p<2.2 .10^{-16}\right)
\end{aligned}
$$

We have adjusted Eq. (1) in order to get identical variance and mean level for the reconstructed and instrumental $T_{\max }$ AMJJAS for the period 1950-2000.

The uncertainty associated with the linear model was estimated using a bootstrap method. Two thirds of the data (calibration samples) were randomly sampled with replacement; the best multiple linear regression was calculated on these data and the quality of the reconstruction was assessed on the last third of the data (verification samples). The uncertainty was obtained using the standard deviation of the verification residuals. After 1000 iterations of this method, we estimated a $\pm 0.55^{\circ} \mathrm{C}$ uncertainty on the linear model.

Further uncertainties on the reconstructed $T_{\max }$ AMJJAS may arise from the physiological response of latewood $\delta^{18} \mathrm{O}$ and GHD to temperature changes (deviations from a linear relationship), from the uncertainty on the proxy measurements and from the uncertainty on the pre-1950 temperature observations. Our analytical protocol warrants an uncertainty on each annual $\delta^{18} \mathrm{O}$ measurement within $\pm 0.25 \%$; the number of pooled samples $(>3)$ also warrants that the effect of individual tree on the averaged annual $\delta^{18} \mathrm{O}$ should be within $\pm 0.54 \%$ o (including the analytical uncertainty). Our estimate for GHD suggests an uncertainty of three days on the stacked Burgundy record. We have used the bootstrap method to test the quality of the linear regression model, taking into account these uncertainties on the proxies by randomly modifying the proxy data within their uncertainty range. In this case, the standard deviation of the residuals obtained over verification sub-datasets was $\pm 0.73^{\circ} \mathrm{C}$ (1000 iterations). Therefore, $85 \%$ of the residuals lie within $\pm 1.1^{\circ} \mathrm{C}(1.5 \sigma)$. In order to have a conservative estimate of the quality of the reconstruction, we consider the error on $T_{\max }$ AMJJAS to be $\pm 1.1^{\circ} \mathrm{C}$ for one year, and thus $\pm 0.35^{\circ} \mathrm{C}(1.1 / \sqrt{ } 10)$ for a decadal (11 years) average. This type of uncertainty is comparable to the one obtained in Switzerland by Büntgen et al. (2006) who combined more than 80 individual tree ring maximum densities using a regional curve standardisation method.

In order to assess the robustness of the reconstruction, 31 years running $R^{2}$ correlation coefficients were calculated between reconstructed $T_{\max }$ AMJJAS and homogenised instrumental $T_{\max }$ AMJJAS. $R^{2}$ coefficients vary from 0.38 to 0.76 and always stand well above the $99.9 \%$ significance level of $0.21 \quad(n=31)$. Correlation coefficients are minima from $\sim 1908$ to $\sim 1935$. During this time period spanning World War I and II, it cannot be excluded that missing data alter the quality of instrumental record homogenisation. The moving of the meteorological stations from "Normal Schools" to airports that took place between 1920 and 1950, indeed yielded breaks and gaps in the thermometric series (MétéoFrance, personal communication). As a matter of fact, a warm bias in eastern France meteorological data was observed by comparison with other peri-Alpine temperature data for the 1940s, and was attributed to difficult observation conditions (R. Böhm, personal communication).

Reconstructed $T_{\max }$ AMJJAS were compared to homogenised instrumental $T_{\max }$ AMJJAS. From 1950 to 1880 , the reconstruction exhibits values progressively colder than the homogenised data, with a difference reaching $1^{\circ} \mathrm{C}$ at the decadal scale in the 1880s (Fig. 3a). The bias between the reconstruction and the homogenised temperature shows no 

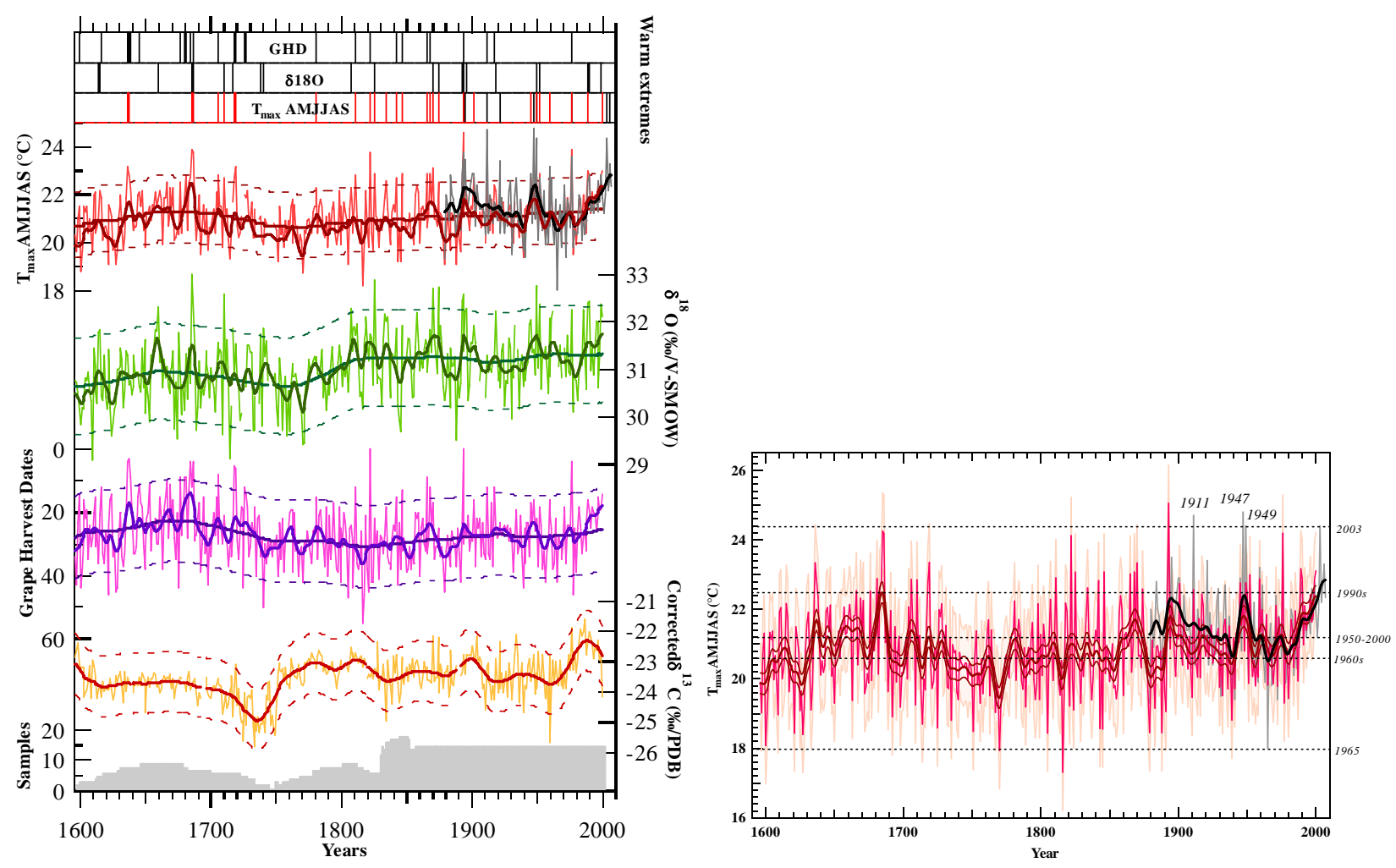

Fig. 3. Proxy records, temperature reconstruction and extreme events.

(a) From bottom to top, total number of pooled beam and tree samples per year (grey line); Fontainebleau $\delta^{\mathrm{x} 3} \mathrm{C}_{\mathrm{corr}}$ data (orange); Burgundy GHD (purple) (note that the scale is inverted in comparison to Figure 2b; Fontainebleau $\delta^{\mathrm{x} 8} \mathrm{O}$ (green); instrumental $T_{\max }$ AMJJAS data (grey) and reconstructed $T_{\max }$ AMJJAS (red). For each of these records, decadal and centennial variations, estimated using an 11 year binomial smoothing, and century-scale trends (SSA) respectively, are displayed with thick solid lines. Parallel thin dotted lines show \pm 1.5 standard deviation from century-scale trend. Missing $\delta^{18} \mathrm{O}$ values (see text in Sect. 2.1 and caption of Fig. 2a) were replaced by the average of the 2 previous and 2 following years.

Warm extremes indicated for GHD, $\delta^{18} \mathrm{O}$ of latewood cellulose and instrumental (black) and reconstructed (red) $T_{\text {max }}$ AMJJAS are displayed as vertical marks in the upper panel. Extremes are defined as deviation above or below the long term average (by more than $1.5 \sigma$ ). For reconstructed $T_{\max }$ AMJJAS: 1636, 1637, 1685, 1686, 1706, 1710, 1718, 1719, 1781, 1811, 1822, 1825, 1834, 1842, 1846, 1865, 1868, 1870, 1874, 1893, 1901, 1945, 1949, 1952, 1959, 1976, 1989 and 2000. For instrumental $T_{\max }$ AMJJAS: 1893, 1895, 1911, 1921, 1947, 1949 and 1976.

(b) Focus on the instrumental (black) and reconstructed (red) Fontainebleau $T_{\max }$ AMJJAS. For an individual year, the reconstruction is associated with $\mathrm{a} \pm 1.1^{\circ} \mathrm{C}(1.5 \sigma$ uncertainty, light pink shading). Decadal trends are highlighted using an 11 year binomial filter (thick reddish brown and black lines resp. for reconstructed and instrumental temperatures). The uncertainty on the decadal average of reconstructed $T_{\text {max }}$ AMJJAS $\left( \pm 0.3^{\circ} \mathrm{C}\right)$ is displayed with thin reddish brown lines. Horizontal lines represent the most extreme warm (2003) and cold $(1965)$ years and extreme warm (1990s) and cold (1960s) decades of the instrumental period, as well as the 1950-2000 average.

correlation with any available meteorological parameter. Extreme warm years are associated to a larger bias. Several factors may explain this reconstruction/instrumental data mismatch (though the trends of the proxies are mutually consistent). It is possible that the initial proxy records could be biased by other factors than $T_{\max }$ AMJJAS, for instance by long term changes in soil water $\delta^{18} \mathrm{O}$ linked with other seasons/other temperatures than $T_{\max }$ AMJJAS, or by changing associations between growing season water stress and maximum temperature (Raffalli-Delerce et al., 2004). Changes in atmospheric composition may also induce changes in tree or grapevine physiology (Bindi et al., 2000). Finally, pre-
1950 meteorological data may be overestimated. In France, "1896" metal type screens (associated with a bias induced by reflected sunshine; Frank et al., 2007) were progressively replaced by Stevenson screens from $\sim 1925$ to 1950 (in 1948 at Paris Montsouris). Tests conducted on the different types of screens suggest that the "1896" screens were associated with an average warm bias up to $0.9^{\circ} \mathrm{C}$ during "average" summer months. 


\section{Results}

In this section, we first describe the proxy records obtained from Fontainebleau tree ring isotopic analyses, and the historical GHD record. Section 3.2 describes the characteristics of this reconstruction from 1596 to 2000 . Finally, the spectral properties of the proxy records and of the reconstruction are analysed in Sect. 3.3.

\subsection{Proxy records}

The $\delta^{18} \mathrm{O}, \delta^{13} \mathrm{C}$ and Burgundy GHD series are shown in Fig. 3a. Eleven years binomial smoothing and low frequency components calculated by a Singular Spectrum Analysis (Spectra software; Ghil, 1997) are reported in order to highlight decadal and centennial trends respectively. The latewood $\delta^{18} \mathrm{O}$ ranges from $29.1 \%$ o to $33.2 \%$ with an average level at $31 \% \circ \pm 0.7 \%$ and with very small auto-correlation $\left(R^{2}=0.10, n=375, p=2.98 .10^{-10}\right.$, one year lag). At a centennial scale, two periods can be distinguished: the first period characterised by a mean $\delta^{18} \mathrm{O}$ level of $\sim 30.8 \%$ (before 1743) is followed by a $0.5 \%$ increase between 1743 and 1812 and by a second plateau between 1812 and 2000 at $~ 31.3 \%$ o. We can rule out that the period of transition (1743 to 1812) has been caused by the introduction of different wood samples (Fig. 3a) as the woods covering the shift all originate from the "Théâtre" site. At a decadal scale, the steepest trend $(0.9 \%$ ) occurs between 1980 and 2000.

Figure $3 \mathrm{a}$ also displays the inter-annual fluctuations of Burgundy GHD. These dates occur in average 27 days after 31 August and display a significant range of inter-annual fluctuations (up to 57 days). GHD are weakly auto-correlated ( $R^{2}=0.05, n=394, p=1.71 .10^{-5}$, one year lag). The 11 years binomial smoothing curve shows that the wine grapes have been harvested as early as they are presently only once during the last 400 years (around 1685). The GHD curve exhibits a steep increase $(-12 \mathrm{j} / 20$ years) during the $1980-2000$ time period.

During the $1743-1812$ period, the GHD and $\delta^{18} \mathrm{O}$ curves show opposite trends: decreasing for GHD, increasing for $\delta^{18} \mathrm{O}$. As already said, the $\delta^{18} \mathrm{O}$ drift cannot be explained by different wood origins (all beams originate from the "Théâtre"). By contrast, the sample quality may be involved in the GHD decreasing tendency. Historical studies suggest indeed that GHD were influenced by anthropogenic effects during this time period (Le Roy Ladurie et al., 2006). Wine producers, in particular those managing the best Burgundy vineyards, may have artificially delayed the GHD to obtain juices with higher sugar contents, maturing to wines with higher alcohol proof.

The lower part of Fig. 3a shows tree-ring $\delta^{13} \mathrm{C}$ data corrected for the progressive $1 \%$ decrease of atmospheric $\mathrm{CO}_{2} \delta^{13} \mathrm{C}$ observed from 1951 to 1996 . The correction applied take into account latitudinal and seasonal fluctuations of $\mathrm{CO}_{2} \delta^{13} \mathrm{C}$ for Northern Hemisphere mid-latitude growing season (M. Leuenberger calibration data, ISONET program). The mean Fontainebleau $\delta^{13} \mathrm{C}_{\text {corr }}$ is $-23.5 \pm 0.7 \%$ and ranges from -25.8 to $-21.6 \%$, with a linear increase of $1.43 \%$ over the past 50 years (mainly due to a step increase in the late 1970s). By contrast with GHD and cellulose $\delta^{18} \mathrm{O}, \delta^{13} \mathrm{C}$ shows a significant auto correlation $\left(R^{2}=0.22\right.$ with one year lag and 0.20 with two years lag). Figure 3 a clearly shows the strong influence of the wood sample number and of their origin on the $\delta^{13} \mathrm{C}_{\text {corr }}$ data. The resulting ruptures in the $\delta^{13} \mathrm{C}_{\text {corr }}$ profile and its autocorrelation are the reasons why we have not used $\delta^{13} \mathrm{C}_{\text {corr }}$ data for the $T_{\max }$ AMJJAS reconstruction (also see supplementary information http://www. clim-past.net/4/91/2008/cp-4-91-2008-supplement.pdf).

\subsection{Fontainebleau $T_{\max }$ AMJJAS from 1596 to 2007}

Using the calibration method presented in Sect. 2.3, we have combined Fontainebleau tree ring cellulose $\delta^{18} \mathrm{O}$ and Burgundy GHD to reconstruct past Fontainebleau $T_{\max }$ AMJJAS. Figure $3 \mathrm{a}$ and $\mathrm{b}$ display Fontainebleau reconstructed $T_{\max }$ AMJJAS from 1596 to 2000 and instrumental $T_{\max }$ AMJJAS, from 1879 to 2007 . The reconstructed maximum growing season temperature ranges from $17.2^{\circ} \mathrm{C}$ to $25.0^{\circ} \mathrm{C}$ with an average level at $20.8^{\circ} \mathrm{C}$.

From 1596 to $1629, T_{\max }$ AMJJAS is characterised by a rather low mean value $\left(20.3^{\circ} \mathrm{C}\right)$ followed by a sharp decadal increase during the 1630s. A warm interval appears from 1635 to 1707 ; it is comparable to the level of 1950-2000 $\left(21.2^{\circ} \mathrm{C}\right)$. The warmest decade is encountered in the $1680 \mathrm{~s}$, with a temperature level reaching $22.5^{\circ} \mathrm{C}$. This warm decade is followed by a sharp cooling in the 1690s, a progressive cooling until the cold 1760 s (mean level back to $20.3^{\circ} \mathrm{C}$ ) culminating into the coldest decade in the early 1770s (mean level reaching $19.5^{\circ} \mathrm{C}$ ). After a sharp rise in the $1770 \mathrm{~s}$, temperatures are then rather stable around $20.6^{\circ} \mathrm{C}$ until 1856 . As described in Sect. 3.1, centennial trends of GHD and $\delta^{18} \mathrm{O}$ differ during this time period (see also the discussion of coherency in Sect. 3.4). As a result, our multi-proxy reconstruction only captures a weak centennial trend over the late 18th-19th centuries.

From the mid 19th century to the mid 20th century, decadal temperatures vary between 20.2 and $21.7^{\circ} \mathrm{C}$, with warm decades in the late 1860s, 1890s and 1940s. Our growing season maximum temperature reconstruction for Fontainebleau therefore captures some warm summers in phase with some Alpine glacier retreat in the middle 17th century (1640s) and with the end of the Little Ice Age (1860s) (Le Roy Ladurie et al., 2006).

Some decades are associated with a surprisingly low interannual variance: 1660 s (due to rather stable $\delta^{18} \mathrm{O}$ signal), 1740s (likely due to missing $\delta^{18} \mathrm{O}$ data), 1920s and 1990s (attributable to the low variance of the GHD signal). The last cold decade is encountered in the 1960s and is followed by a prolonged warming at a $0.8^{\circ} \mathrm{C} /$ decade rate. This rate is not exceptional. For instance, during the 1670 s a $1.8^{\circ} \mathrm{C}$ 
increase per decade is observed. The specificity of the recent year trend rests with its unprecedented duration. The warmest decades are observed in the 1990s to 2000s, 1680s, 1940 s and 1890 s. The recent warm years have been standing $1.5 \sigma\left(0.3^{\circ} \mathrm{C}\right)$ above the previous extreme warm decade (1680s) only since 2003.

Extreme years (those deviating by more than $1.5 \sigma$ from the centennial average) have been identified on the reconstructed temperature, GHD and $\delta^{18} \mathrm{O}$ records (Fig. 3a). The years recognised as extreme are not the same in the $\delta^{18} \mathrm{O}$ and GHD records (except 1686 and 1893). The heat waves do not necessarily impact $\delta^{18} \mathrm{O}$ and GHD similarly, according to their timing and duration. For instance, years with warm springs followed by average summers, may have early GHD and average to low $\delta^{18} \mathrm{O}$. This is the case in 1901, 1915 and 1952. Specific hydrological effects are also expected to have different imprints on proxy records. The instrumental $T_{\max }$ AMJJAS exhibit 7 extreme years since 1879. Respectively 2 and 3 out of the 7 years are also extreme in the $\delta^{18} \mathrm{O}$ and GHD records. Obviously, the $\delta^{18} \mathrm{O}$ proxy is not highly capable in extreme values reconstruction. This is in agreement with Etien et al. (in press) who concluded that the inter-tree isotopic variability increased during extreme years leading to a deteriorated accuracy of the $\delta^{18} \mathrm{O}$ values. Nevertheless, for instrumental period, all the extreme warm values in the $\delta^{18} \mathrm{O}$ record correspond to hot (above 1 standard deviation in the measured $T_{\max }$ AMJJAS series) or dry years (as 1918 or 1989).

From 1596 to 2000, the extreme reconstructed $T_{\max }$ AMJJAS are, by decreasing magnitude: 1893, 1685, 1976, 1686 and 1822 for the extreme warmth and 1816, 1770, 1600, 1627 and 1621 for the extreme coldness. The 1685-1686 years were reported to be warm and dry elsewhere in Europe, in England (Manley, 1974) and Switzerland (Pfister, 1985). The unusual character of 1686 is also attested by historical sources describing an intense heat wave associated with exceptional massive grasshopper invasions in southern France (Le Roy Ladurie, 1966). According to Garnier (1967), 1822 had a warm and particularly dry growing season in all the Western Europe too. 1893 and 1976 stand out on the instrumental $T_{\max }$ AMJJAS record as extreme warm years as well.

\subsection{Spectral properties}

Spectral analyses of Fontainebleau tree-ring $\delta^{18} \mathrm{O}$, Burgundy GHD and instrumental and reconstructed $T_{\max }$ AMJJAS described in part 3.1. and 3.3. have been conducted with the Analyseries software (Paillard et al., 1996) using a Blackman-Tuckey method with Bartlett windows. The resolution has been adjusted to capture $50 \%$ of variance, with a bandwidth of $0.024 \mathrm{yr}^{-1}$. The results have been compared to calculations conducted with other methods (Maximum Entropy, Multi Taper Method, Singular Spectrum Analysis) and have been shown to be robust with respect to the spectral analysis methodology. Analyses have been performed for the instrumental period (A.D. 1879 to 2000) and over three time intervals of similar length (148 years): 1596 to 1743,1748 to 1896 , and 1853 to 2000.

Over 1879-2000, the instrumental signal of $T_{\max }$ AMJJAS exhibits multi-decadal variability at periodicities of $\sim 55$ and 25 years, a periodicity of $\sim 13$ years and an inter-annual variability expressed as broad peaks at 7-8 years and at $\sim 5-6$ years (Fig. 4a). $\delta^{18} \mathrm{O}$ and GHD power spectra are globally mutually consistent and they both fail to capture the $\sim 7-8$ years peak. However, at the lowest (5-6 years) and highest periodicities ( $\sim 45$ years), the $\delta^{18} \mathrm{O}$ power spectrum is in closer agreement with the instrumental temperature spectrum than the GHD spectrum. The reconstruction captures the general shape of the instrumental temperature power spectrum and has more similarity and coherency with it than each individual record, pointing to the improvement obtained by combining the two records.

The power spectrum obtained for the reconstructed $T_{\max }$ AMJJAS over the period 1853-2000 and over 1879-2000 show similar periodicities but with an enhanced peak at $\sim 6$ years (Fig. 4b).

The comparison of the power spectrum of 1748-1895 (Fig. 4c) to the one of 1853-2000 reveals that the coherency of the $\delta^{18} \mathrm{O}$ and GHD power spectra: i) is stronger at the inter-annual scale (for periodicities between 5 and 9 years), ii) decreases at the decadal and multi-decadal scales. Inside the 1748-1895 period, in the sixty-four years long interval from 1748 to 1812 (see Sect. 3.1), the $\delta^{18} \mathrm{O}$ and GHD trends are opposite, while they are in phase, at the decadal scale, from 1850 to 1895 . These different changes of the $\delta^{18} \mathrm{O}$ and GHD records can explain the lack of coherency of the power spectra at periodicities above 7 years. Rigorously, the analysis of the power spectrum of the reconstructed $T_{\max }$ AMJJAS has to be restricted to the periodicities below 7 years. In the range 5-7 years, the reconstructed $T_{\max }$ AMJJAS shows a power spectrum quite similar to the one observed for the last 148 years.

From 1596 to 1743 , except at the periodicity $\sim 22-23$ years, $\delta^{18} \mathrm{O}$ and grape harvest data show a poor mutual coherency (Fig. 4d). The pattern of the reconstructed $T_{\max }$ AMJJAS spectrum of this time period differs from the pattern of the instrumental period, particularly in the $7-13$ years range.

For the instrumental period, or for the other time slices, the reconstructed $T_{\max }$ AMJJAS fails to reproduce the $\sim 7$ 8 years peak of the instrumental $T_{\max }$ AMJJAS. The spectra of the $\delta^{18} \mathrm{O}$, GHD and reconstructed $T_{\max }$ AMJJAS reveal a persistence of the $8-9$ years, of multi-decadal ( $\sim 25$ years), and interannual $(\sim 5-6$ years) periodicities over the three 1.5 century long intervals. By contrast, there seems to be significant shifts of the spectral power expressed in the 6-7 and 1013 years periodicities. At the decadal scale, the variability through time of the reconstructed $T_{\max }$ AMJJAS power spectrum may be attributed to worsening of the proxies back in time. The correspondence of $\delta^{18} \mathrm{O}$ in recent (living trees) and 
a)

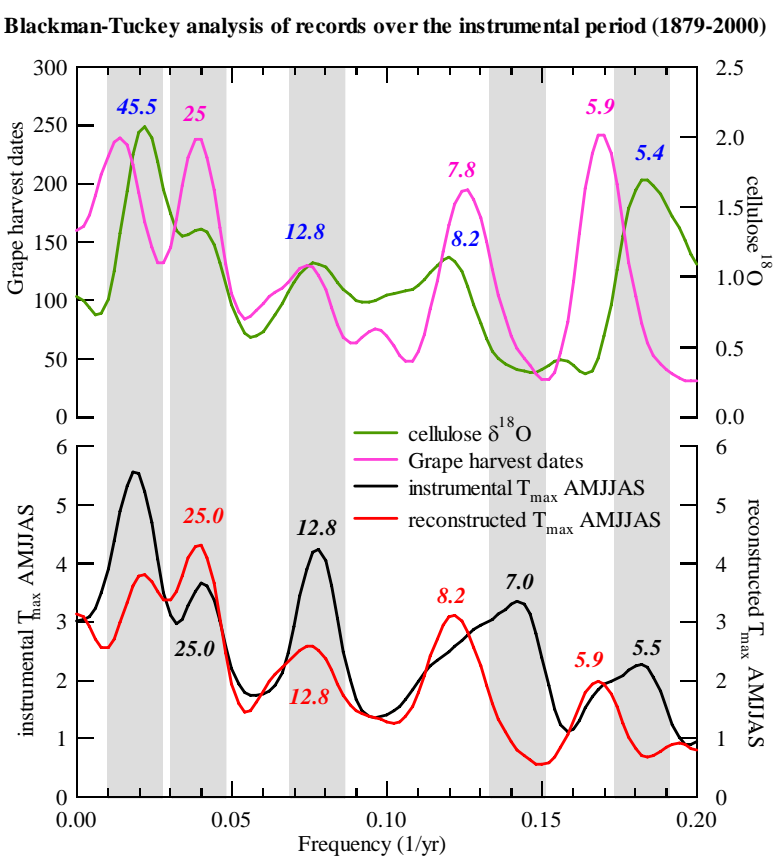

c)

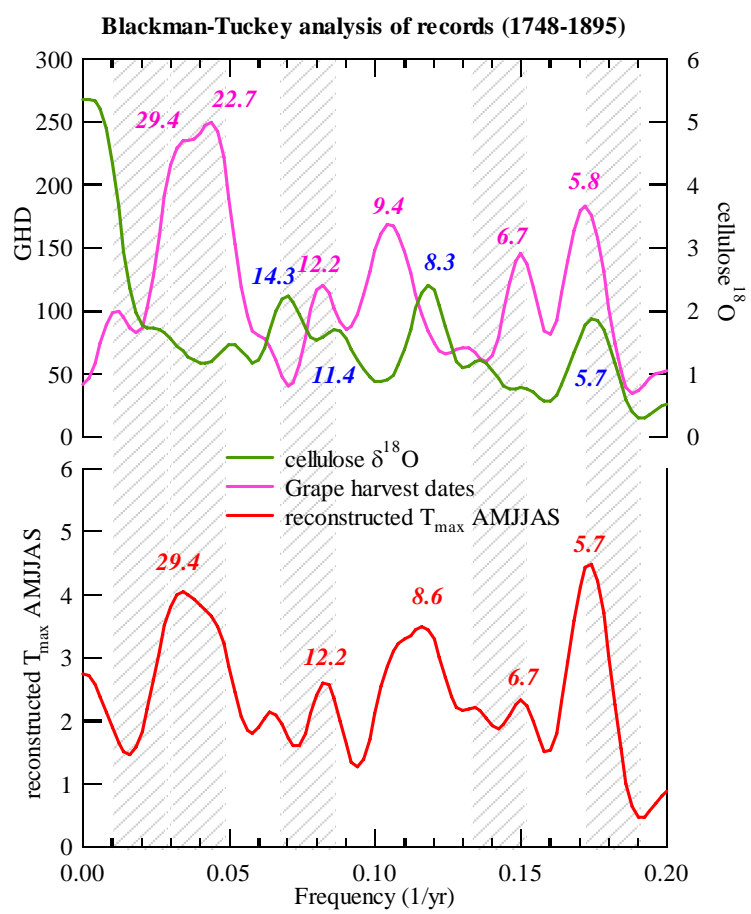

b)

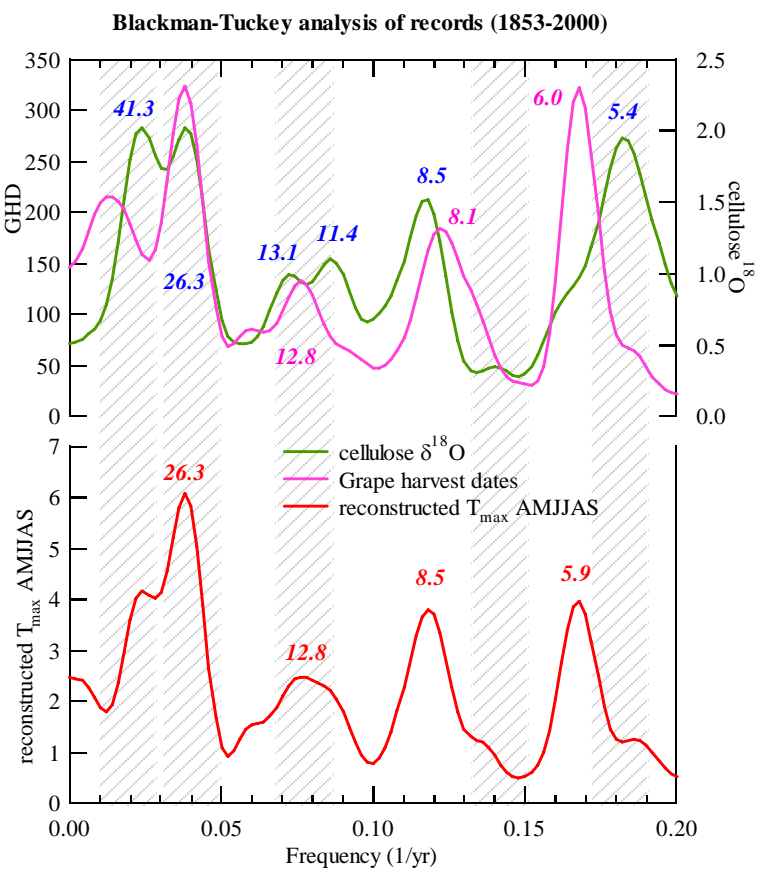

d)

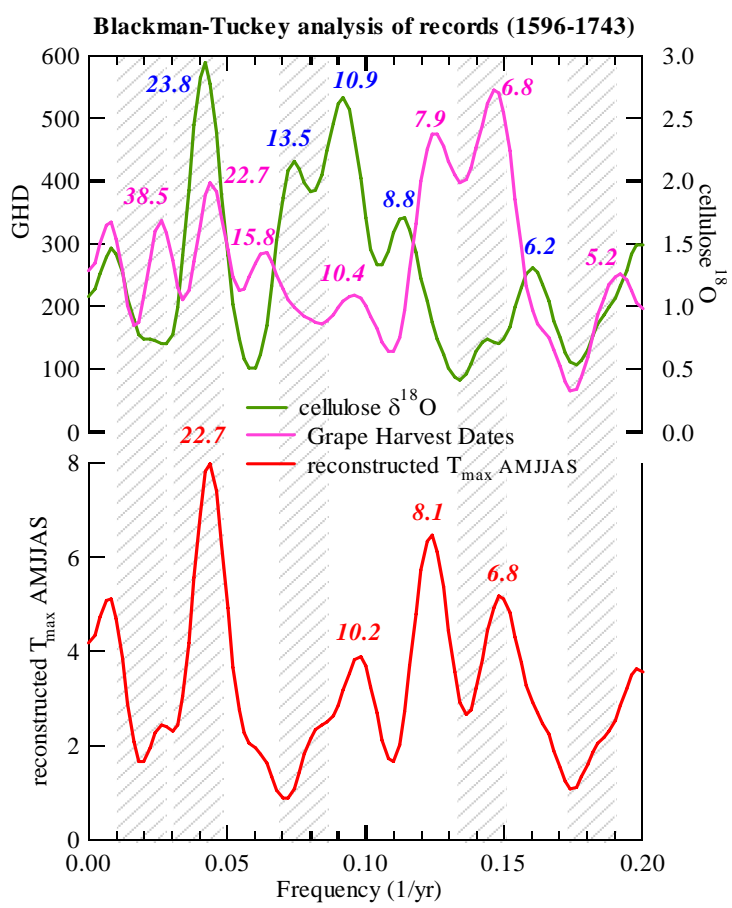

Fig. 4. Spectral analyses. Spectral power versus frequency (1/yr) calculated with the Analyseries software (Paillard, 1996) using a BlackmanTuckey method with Bartlett windows and a resolution adjusted for $50 \%$ of variance.

(a)Analysis of the period 1879-2000 for Fontainebleau tree-ring latewood cellulose $\delta^{18} \mathrm{O}$ (green), historical Burgundy GHD (purple), Fontainebleau homogenised instrumental $T_{\max }$ AMJJAS (black) and reconstructed $T_{\max }$ AMJJAS (red). The values of the periods corresponding to the maxima in spectral power are displayed. Grey rectangles highlight the major periodicities found in the instrumental record. (b) Same as Fig. 4a for 1853-2000. The shaded areas correspond to the major periodicities of the instrumental record (1879-2000; as in (a)).

(c) Same as Fig. $4 \mathrm{~b}$ for $1748-1895$.

(d) Same as Fig. 4c for 1596-1743. 
ancient (beams) wood shows that, at least at a two-century scale, there is no signal deterioration (Sect. 2.1.). An alternate explanation would be that the periodicities of forcing parameters had changed with time.

\section{Discussion}

In this section, we compare our bi-proxy temperature reconstruction for Fontainebleau with (4.1) early instrumental data from the few long western European records; (4.2) all the available estimates of western Europe growing season temperature based on different sets of proxies and different extrapolation methods.

4.1 Comparison with early instrumental data from Paris, De Bilt (Netherland) and Central England

In the previous section, we have discussed the relevance of our record in terms of past changes in temperature, addressing changes in mean state, trends, decadal, inter-annual variability and extreme years. Because of a calibration built only on the 20th century, it is of major interest to compare this multi-proxy reconstruction with early instrumental measurements.

The longest available temperature record in Europe is the Central England temperature series (CET, Manley, 1974) starting in 1659. In Paris (France), some early instrumental data are available for temperatures (Legrand and Le Goff, 1992) or precipitation (Slonosky, 2002). However, these early instrumental data are probably affected by changing observation conditions and have not been homogenised. The precipitation, are not correlated with our data $\left(R^{2}=0.09\right.$, $n=116, p=0.0009$ ), what could be expected from the calibration study over the 20th century (Etien et al., in press). For the maximum AMJJAS temperature of Morin (in Legrand and Le Goff, 1992), the correlation though significant is poor $\left(R^{2}=0.15, n=37, p<0.05\right)$. These results question the reliability of this early instrumental series. The earliest available homogenised temperature record in France is obtained from Paris Montsouris (1873), a dataset used for the homogenisation of the oldest Fontainebleau data.

Fontainebleau instrumental $T_{\max }$ AMJJAS is well correlated $\left(R^{2}>0.64, p<0.05\right)$ with 20 th century temperature from South-Western France to Northern Germany (Etien et al., in press). Therefore, the comparison of our reconstruction with long homogenised temperature data in North-Western Europe is meaningful. We have used two datasets of ancient instrumental meteorological observations from other areas: Central England temperature record from Manley (1974), from 1659 to 1973, updated by Parker et al. (2005), and De Bilt (Netherlands) temperature from Van Engelen and Geurts (1983-1992) updated with the EC EMULATE project (http://www.cru.uea.ac.uk/projects/emulate/) from 1706 to 2006 (Fig. 5a).
The instrumental mean growing season temperature series of Central England, available from 1659 to 2005, ranges from 10.9 to $14.9^{\circ} \mathrm{C}$ with an average level at $13.6 \pm 0.7^{\circ} \mathrm{C}(1 \sigma)$. $T_{\max }$ AMJJAS is available only from 1878 to 2005 . It ranges from 14.9 to $19.7^{\circ} \mathrm{C}$ with a mean value of $17.4 \pm 0.9^{\circ} \mathrm{C}$. The $T_{\text {mean }}$ AMJJAS of De Bilt, available from 1706 to 2006, has an average level of $13.9 \pm 0.7$ and varies between 11.7 and $16.2^{\circ} \mathrm{C}$. $T_{\max }$ AMJJAS, available from 1901 to 2006 , ranges from 16.9 to $21.9^{\circ} \mathrm{C}$ with an average level at $19 \pm 0.9^{\circ} \mathrm{C}$.

$T_{\text {mean }}$ and $T_{\max }$ show a good correlation $\left(R^{2}=0.80\right.$ and 0.94 respectively at De Bilt and in Central England). Moreover, the warming trend of the second half of the 20th century is imprinted on $T_{\text {mean }}$ and $T_{\max }$. $T_{\text {mean }}$ and $T_{\max }$ being consistent, we compared our reconstruction with early instrumental $T_{\max }$ data, but also with $T_{\text {mean }}$ data to take advantage of longer records. For the growing season, strong correlations are observed between $T_{\max }$ at Fontainebleau and: Central England $T_{\max }\left(R^{2}=0.39\right.$, from 1878 to 2000$)$, Central England $T_{\text {mean }}\left(R^{2}=0.27\right.$, from 1659 to 2000$)$, De Bilt $T_{\max }$ ( $R^{2}=0.27$, from 1901 to 2000$)$, De Bilt $T_{\text {mean }}\left(R^{2}=0.32\right.$, from 1706 to 2000).

We have analysed the stability of Fontainebleau/Central England and Fontainebleau/De Bilt correlations by calculating a 51 years running $R^{2}$ correlation (Fig. 5b). For both sites, the best correlations with Fontainebleau appear over the 19th century and the second half of the 20th $\left(R^{2}\right.$ between 0.30 and 0.55 ). The $R^{2}$ are above the significancy threshold at $5 \%$ (dashed line; $R^{2}=0.2$ for $n=51$ ), except during 1920 1930 and before 1700. By a bootstrap method, we calculated a minimum uncertainty $(1 \sigma)$ of 0.2 on $R^{2}$. Therefore, most variations of $R^{2}$ through time (1920-1930 and 1700 excepted) are not statistically significant and we can conclude that the signal is globally stable. This result suggests that the high coherency between Northern France, Central England and the Netherlands growing season temperatures observed from instrumental data persists back in time. The comparison of our reconstructed $T_{\max }$ AMJJAS with Central England and De Bilt data reveals a mismatch at the decadal scale in the early 20th century $\left(R^{2}\right.$ under the threshold value during 1920-1930). Our reconstruction shows a maximum centred on 1925 which is not seen in the other records (Fig. 5a). This may explain the lower correlation obtained for the 20th century. Again, we highlight a problem occurring in the interval between World War I and II.

Prior to the 19th century, instrumental records must be taken with caution. De Bilt data are independent of Central England temperature from 1740 onwards. Before 1740, Central England temperature data have been used for the homogenisation of $T_{\text {mean }}$ at De Bilt. The sources used by Manley to produce the ancient Central England Temperature are not known (P. Jones, personal communication). It is expected that Central England temperature may be biased in summer (overestimation of warmth due to observation methods) prior to 1740 (P. Jones, personal communication). The significant inter-annual correlations $\left(0.2<R^{2}<0.45\right)$ between 

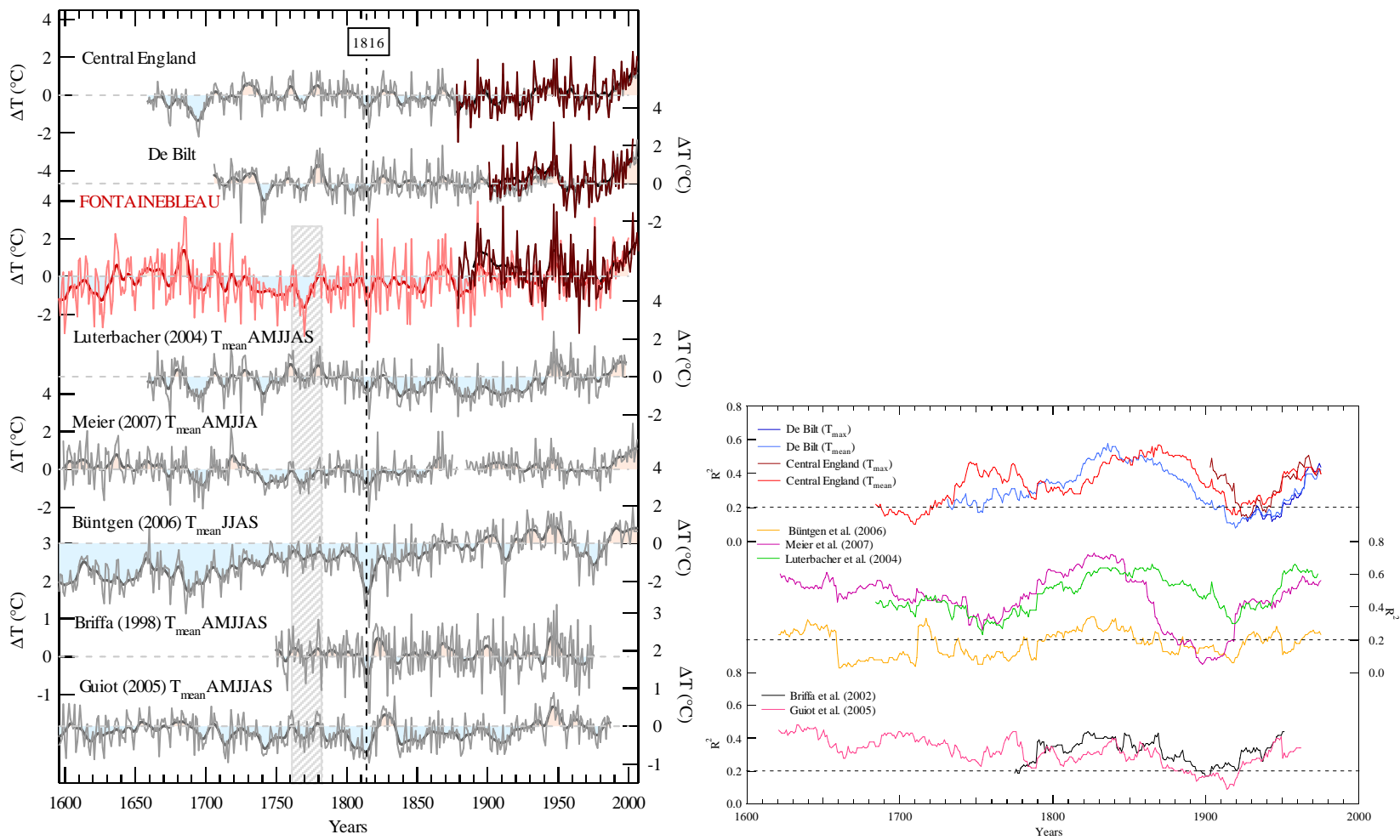

Fig. 5. Comparison of Fontainebleau reconstruction with European early instrumental and proxy based reconstructions of air temperature anomalies (normalised to 1960-1990).

(a) From top to bottom. Time series of Central England and De Bilt (Netherlands) April-September mean (grey lines) and maximum (reddish brown lines) temperatures; homogenised instrumental (black) and reconstructed (red) records of Fontainebleau $T_{\text {max }}$ AMJJAS; reconstructions of AMJJAS mean temperature for the four grid-points closest to Fontainebleau in the multi-proxy reconstruction of Luterbacher et al.(2004); reconstruction of Switzerland AMJJA mean temperature based on GHD (Meier et al., 2007); reconstruction of Switzerland and Austria high elevation JJAS mean temperature based on tree-ring maximum densities (Büntgen et al., 2006); reconstructions of AMJJAS mean temperature for Southern Europe from Briffa et al. (2002), Guiot et al. (2005). The decadal variations of each record are highlighted using an 11 year binomial smoothing (thick lines). For the last two reconstructions, note that the vertical axes have been amplified by a factor of 2 . The cold and warm periods are emphasized respectively by a blue and a pink filling up. The vertical shaded area shows the M shape over 1760-1780. The vertical dotted line shows 1816, the year after the Tambora eruption.

(b) 51 years Running correlation coefficients $\left(R^{2}\right)$ obtained between Fontainebleau reconstructed $T_{\text {max }}$ AMJJAS and instrumental temperature in Central England (red) and at De Bilt, NL (blue); mean air temperature reconstructions in the Fontainebleau area by Luterbacher et al. (2004; average of four grid points; green), in Switzerland by Meier et al. (2006; purple) and by Büntgen et al. (2006; orange) for high elevation sites; reconstructions at the Southern Europe scale according to Briffa et al. (2002, grid point 14; black), Guiot et al. (2005; pink). Significance threshold of $R^{2}$ using a Student $t$-test (at 95\%) is displayed as dashed lines.

reconstructed $T_{\max }$ AMJJAS at Fontainebleau and De Bilt and Central England $T_{\text {mean }}$ AMJJAS over the 17th and 18th centuries support the quality of reconstructions and early instrumental records, despite these known biases.

At the decadal and centennial scales, there are some discrepancies between Fontainebleau reconstructed $T_{\max }$ AMJJAS and early instrumental records at De Bilt and in Central England (Fig. 5a). These last records have no centennial variability and do not capture the reconstructed warm interval of the late 17th-early 18th century nor the cold interval of the 18th to 19th centuries. At the decadal scale, our reconstruction has $\sim 50 \%$ more magnitude of variation than the instrumental series. It is also remarkable that the warmest and coldest decades differ between De Bilt, CET and Fontainebleau. For instance, the 18th-19th century warmest decade of De Bilt is obtained in the 1780s, while it is observed is the 1860s at Fontainebleau and 1730s in Central England. The Fontainebleau coldest decade is observed in the 1760s, versus the 1740s in De Bilt and the 1690s in Central England.

The comparison between homogenised temperature data and our reconstruction suggests that pre-1950 growing season temperatures may be overestimated during warm and sunny years, as expected from the lack of shading of the past meteorological instruments. Moreover, our reconstruction shows persistent coherency with the Manley Central England 
temperature long record. Such a similarity is expected from the instrumental period and is therefore confirmed over several centuries. This comparison confirms the quality of the work conducted by Manley to build a long homogenised temperature time series. In France, early instrumental temperature data are available in Paris since 1675 but they have not been homogenised. The comparison both with the Central England data and with our reconstruction clearly questions their quality and their use in European reconstructions. An effort such as the one conducted by Manley should be performed on these early French instrumental data.

\subsection{Comparison with reconstructions based on proxies}

We have compared our reconstruction with other growing season/summer temperature proxies based reconstructions for northern France and neighbouring areas. Figure 5a displays the Luterbacher et al. (2004) $T_{\text {mean }}$ AMJJAS data averaged over the four grid points closest to Fontainebleau. This gridded $\left(0.5^{\circ} \times 0.5^{\circ}\right)$ European monthly reconstruction is based on instrumental series including Central England, De Bilt, Paris and Nantes (Fr), documentary records of seaice and temperature, Greenland ice core and Scandinavia and Siberia tree-ring proxy records. The figure also shows two reconstructions focused on Switzerland, one for $T_{\text {mean }}$ AMJJA based on GHD (Meier et al., 2007) and one for high elevation $T_{\text {mean }}$ JJAS based on tree ring maximum density (Büntgen et al., 2006). The western Europe $T_{\text {mean }}$ AMJJAS reconstruction of Guiot et al. (2005) is also presented; this multi-proxy reconstruction uses Burgundy and Switzerland GHD, together with different tree ring proxies and documentary records (including Switzerland reconstructions). The "Southern Europe" $T_{\text {mean }}$ AMJJAS reconstructed by Briffa et al. (2002) using tree ring width and density records from different locations (none in France) is shown too.

The Luterbacher et al. (2004) series exhibits a centennial scale cold phase over the 19th-early 20th century, quite later than our reconstruction. At the decadal scale, there is a fair coherency between the two reconstructions. The prominent M shape in the Luterbacher et al. (2004) series across 17601780 is also observed with varying magnitudes in all the reconstructions. The correlation coefficients between our reconstruction and Luterbacher et al.'s (2004) range between $R^{2} \sim 0.35$ in the 18 th and early 20th century and $\sim 0.55$ in the 19th century and second half of the 20th (Fig. 5b). The overall good coherency may result from the consistency of Burgundy and Swiss GHD $\left(R^{2}=0.47, n=448, p<0.001\right)$. As a matter of fact, a good and persistent correlation is obtained between our reconstruction and $T_{\text {mean }}$ AMJJA based on Swiss GHD (Meier et al., 2007) $\left(R^{2} \sim 0.45\right.$ except in the early 20th). Despite differences in the relative magnitude of cold and warm decades, the Meier et al.'s (2007) reconstruction exhibits centennial variations, with mild temperatures in the 17th century, cold decades in the 18th century and 19th century, quite similar to those of our reconstruction (Fig. 5a).
This is in contrast with the Swiss $T_{\text {mean }}$ JJAS reconstruction of Büntgen et al. (2006) based on completely different proxies (high elevation tree ring width density). Unlike all the other time series, this reconstruction exhibits a multi-century increasing trend culminating in the mid 20th century. In addition to this long term trend, the Büntgen et al.'s (2006) data also show milder decades in the 1610s, 1660s and 1680s, and cold decades in 1680-1700, and 1810s, identified in all northern Europe time series. The overall correlation with our reconstruction remains quite low $\left(R^{2} \sim 0.10\right.$ to 0.20 according to the century).

Finally, we compare the Fontainebleau reconstruction with large scale temperature reconstructions from Briffa et al. (2002) ("southern Europe") and Guiot et al. (2005) ("western Europe"). Note that the variations of the Briffa and Guiot reconstructions are twice smaller than for all other time series (vertical axes ranges have been adjusted on Fig. 5a for readability). The Briffa et al.'s (2002) reconstruction for southern Europe has almost no centennial trend but captures decadal variations parallel to our reconstruction with different relative intensities (Fig. 5a). The correlation coefficient is above the significancy threshold. Its lowest values are obtained for the late 18th and for the late 19th-early 20th $\left(R^{2} \sim 0.20\right)$. However, the variations of $R^{2}$ are not highly significant. The values of the correlation coefficients between our reconstruction and the Guiot et al.'s (2005) are similar to Briffa et al.'s (2002) (although less good than with Central England, De Bilt, Luterbacher et al., 2004 and Meier et al., 2007). At the centennial scale, the Guiot et al.'s (2005) reconstruction is quite coherent with ours, showing mild temperatures prior to 1700 , and cooler temperatures over the 18th to 19th centuries (Fig. 5a). This reconstruction exhibits a marked warm decade in the 1820 s, only seen in the Briffa et al.'s (2002) with similar magnitude; this may arise from the common use of tree ring data in these two reconstructions.

The comparison with the other western European temperature reconstructions raises several questions. First, this comparison is obviously limited by the fact that different targets were used (maximum versus mean temperature; AMJJAS versus other parts of the growing seasons). Second, despite a coherent evolution of growing season temperatures at the European scale during the instrumental period (Etien et al., in press), regional differences are observed. For instance, 20th annual maximum temperature trends are larger in southern France and in the Alps than in northern France (Moisselin et al., 2002). Therefore, it must not be expected to obtain similar temperature reconstructions when using proxies from different European locations and elevations. Similarly, European heat waves can be centered on different locations. For instance, the 2003 heat wave is clearly centered on Switzerland and central eastern France (Schär et al., Nature, 2004). This heat wave was suggested to be unprecedented over the past centuries, both from Burgundy GHD (Chuine et al., 2004) and from European multi-proxy reconstructions (Luterbacher et al., 2004). We plan to expand our 
Fontainebleau tree ring analyses for the period since 2000, using new tree sampling, in order to assess the response of our proxy data to this extreme warmth, particularly remarkable in term of minimum August temperature.

There is a good coherency between our reconstruction and those obtained using documentary data especially from Switzerland (Meier et al., 2007; Luterbacher et al., 2004). This is coherent with the instrumental period showing similar fluctuations and trends in northern France and Swiss valleys. Some multi-proxy reconstructions have less variance than ours (e.g. Briffa et al., 2002 or Guiot et al., 2005). This can be caused by the combination of multiple predictors and the extrapolation methods towards poorly documented areas. Finally, the tree ring based reconstruction of Büntgen et al. (2006) appears as an outlier, with a strong multi-centennial warming trend and a strong decadal cooling in the 1810s. One may question whether this specific signal is linked with the proxies (high elevation tree response to climate and environmental factors), with the statistical methods (detrending), or with the actual high elevation versus low elevation climatic changes including different cloudiness and insolation variations (Auer et al., 2007). Progress could be made by conducting $\delta^{18} \mathrm{O}$ analyses on some of the long tree ring datasets used by Büntgen et al. (2006) in order to compare the different tree ring indices.

\section{Conclusion and perspectives}

Our initial target was to produce a reliable temperature record in an area poorly documented prior to the homogenised instrumental period (northern France). Despite the availability of several European-scale temperature reconstructions and long instrumental records, it remains important to produce new local temperature reconstructions, in order to test the coherency of other reconstruction and extrapolation methods. Past temperature reconstructions clearly raise the question of signal to noise. The reduction of the noise (or biases) can be obtained either by expanding the spatial scale of the reconstruction and combining many different sources of information, or by selecting the best possible proxy records at a local scale, which is our approach here.

In this paper, we have combined a Burgundy GHD record with new $\delta^{18} \mathrm{O}$ measurements conducted on timber wood and living tree cellulose from Fontainebleau castle and Fontainebleau forest. Using these two independent datasets, we have applied a linear calibration method developed and tested against 20th century instrumental data (Etien et al., in press) to build a temperature reconstruction for northern France. The strength of our approach lies in the quality of the original proxy records and in their strong relationship with growing season maximum temperature, demonstrated for the 20th century. By contrast with "classical" dendroclimatology, we have not deployed sophisticated statistical data treatment to combine different tree sets; and contrary to many other temperature reconstruction methodologies, we have used continuous and homogeneous proxy records.

Due to the availability of timber wood, the size of the tree cores and rings and the amount of matter required for the isotopic analyses, it was not possible to conduct isotopic analyses on individual tree samples. The pooling of different tree samples and different timber wood populations may introduce heterogeneities in the proxy records. The available inter-tree comparisons suggest that these effects remain limited for $\delta^{18} \mathrm{O}$ but obvious for $\delta^{13} \mathrm{C}$. This last parameter appears influenced by tree and age effects and is therefore not used in our reconstruction. An earlier study conducted on old Juniperus sp. from Pakistan (Treydte et al., 2006) suggested that centennial $\delta^{18} \mathrm{O}$ trends may be tree-dependent. We cannot rule out the fact that the introduction of different tree and timber wood samples could have a second-order effect on the $\delta^{18} \mathrm{O}$ record. The difference between the two overlapping parts of the $\delta^{18} \mathrm{O}$ signal at Fontainebleau may be ascribed to such an age effect (cellulose of biologically young rings of living trees being $0.46 \%$ oxygen richer than biologically old rings collected in beams). Future studies should be conducted on young and old trees covering the same time period in order to explore this problem.

Another source of uncertainty lies in multiple climatic influences on proxy records. Calibration studies conducted on French Quercus sp. latewood cellulose $\delta^{18} \mathrm{O}$ have clearly shown a strong link with growing season temperature but also with water stress parameters (Etien et al., in press; Raffalli-Delerce et al., 2004; Danis et al., 2006). If past climate changes are associated with different weather regimes, it is possible that different sources of bias alter the relationship between latewood cellulose $\delta^{18} \mathrm{O}$ and growing season maximum temperature. These sources of uncertainties may arise from factors influencing precipitation $\delta^{18} \mathrm{O}$, and not or indirectly linked to temperature, such as moisture origin, continental recycling, convection, droplet reevaporation. They can also be attributable to factors controlling the cellulose $\delta^{18} \mathrm{O}$ through leaf water enrichment, linked with relative humidity and water stress.

We have therefore decided to build a temperature reconstruction that would not only rely on this single proxy record but would also use Burgundy GHD. Similarly, grape harvest dates may be biaised by anthropic, non climatic factors, and influenced by aspects of the vine phenology regulated by temperature, but also by insolation and water stress (e.g. Van Leeuwen et al., 2003). Water stress and insolation, are expected to affect differently grape maturation and water enrichment in oak leafs, due to different plant physiological processes and to different impacts of water stress ${ }^{1}$,

\footnotetext{
${ }^{1}$ As western Europe tree ring widths characteristic years have been suggested to be influenced by droughts (Briffa, 2000; Etien, et al., in press), we have tried to match characteristic growth years with $\mathrm{d} 18 \mathrm{O}$ data, without any convincing result. Therefore, we could not use the different tree ring indices to detect hydrological biases.
} 
we have tried to match characteristic growth years with $\delta^{18} \mathrm{O}$ data, without any convincing result. Therefore, we could not use the different tree ring indices to detect hydrological biases, insolation and temperature at different periods of the growing season. For instance, GHD were very early in 2007 (i.e. late August- early September in Burgundy) due to April 2007 western European heat wave; such an early temperature anomaly is expected to affect only part of the latewood cellulose isotopic composition. It is possible that combinations of intra-seasonal variability of temperature and precipitation may explain why extreme events cannot be simultaneously identified in GHD and cellulose $\delta^{18} \mathrm{O}$ data. The interest of combining the two proxies appears therefore clearly in terms of seasonal temperature signals. In the future, these types of biases could be tested using proxy models forced by the temperature and precipitation records of the instrumental period, using vine phenology models and land surface vegetation models, and using regional atmospheric models simulating water stable isotopes

The quality of the temperature reconstruction is clearly improved when combining the two records rather than using one of them, both in terms of interannual variability, extreme values, but also in terms of decadal and centennial temperature trends (see Sect. 2.3 and Etien et al., in press). GHD and $\delta^{18} \mathrm{O}$ data do not have the exact same power spectrum as growing season temperature, with varying weights of frequencies ranging between 6 and 25 years. Their linear combination exhibits more comparable spectral properties with the instrumental record. It is questionable whether we should combine the two records using a simple linear calibration as we have done here, or whether more sophisticated methods should be deployed, for instance by retaining only high frequencies for GHD.

What is the added value of our reconstruction? We have estimated an uncertainty of $1.1^{\circ} \mathrm{C}(1.5 \sigma)$ on individual growing season maximum temperature reconstructions. This uncertainty results from uncertainties on analytical measurements and on the stability of the linear correlations over the 20th century. The good point is that we are able to assess this uncertainty, which is not the case for many documentary sources (diaries etc.), and even not the case for early instrumental temperature data. It is possible that thermometer measurements could be biased by up to $1-2^{\circ} \mathrm{C}$ for maximum summer temperature due to inadequate thermometer shading apparatus (R. Böhm, personal communication). We suggest that homogenised maximum temperature data from Fontainebleau area could be biased and could overestimate summer warmth in the early 20th century, a point which has implications for detection/attribution studies and analysis of extreme warmth events.

One may expect that the uncertainty on the reconstructed temperature should increase back in time. In principle, the introduction of different tree populations of unknown species (Quercus robur or petraea) and origin is expected to induce further uncertainty. Both dendrochronological and historical information supports the Fontainebleau forest origin of the timber wood. Genetic analyses may in the future help to select timber wood from specific species. Sources of heterogeneities are limited for the Burgundy GHD record built using only one variety ("Pinot noir"). However, the 17th century data are obtained from the Dijon documentary sources only, with more variance than when the GHD record incorporates documentary sources from different places. We have however no method to quantify these sources of uncertainties.

The comparison between our data and temperature estimates for Europe is highlighting. Before 1750, Meier et al.'s (2007), Luterbacher et al.'s (2004) and Guiot et al.'s (2005) reconstructions are correlated with our reconstruction $\left(R^{2}>0.4\right)$. This feature is stable over $1600-1750$. At the contrary, the correlation coefficients between our reconstructed temperatures and CET show a large decrease from 1750 to 1600 (before $1730, R^{2}$ is even inferior to the significancy threshold). The construction of the CET reference "instrumental" record still remains a mystery, and is described by Manley himself as "built up [...] largely by the exercise of judgment on series of observations that are formidably open to doubt [...]". The comparison between our reconstruction and Manley mean growing season temperature data provides an independent control on the quality of CET data. We show that (i) our reconstruction preserves more variance back in time, at decadal to centennial scales, probably because it is not distorted by homogenisation or detrending methods; (ii) different reconstruction of growing season temperatures are consistent through time but diverge with the CET reconstruction from 1750 backwards. This comparison provides a strong and independent verification of the quality of the pionneer work of Manley.

Further works will be conducted to compare the $\delta^{18} \mathrm{O}$ data from wood cellulose provided by transects of different tree species in Europe to analyse the spatial and temporal coherency between $\delta^{18} \mathrm{O}$ records prior the 20th century, following the approach of Treydte et al. (2007). The decadal variability will be also compared with other precipitation $\delta^{18} \mathrm{O}$ records such as those obtained from benthic ostracods from deep peri-Alpine lakes, reflecting multi-annual precipitation averaged $\delta^{18} \mathrm{O}$ values (Von Grafenstein et al., 1998). Precipitation isotopic composition can now be simulated by regional atmospheric models equipped with the modelling of water stable isotopes (Sturm et al., 2005). Such simulations need to be used in order to improve our understanding of the processes relating climate variability, precipitation isotopic composition, and tree ring latewood cellulose isotopic composition.

Acknowledgements. We are grateful to P. Jones and E. Le Roy Ladurie for clarifying comments on Manley (1974)'s reconstruction, David Lister for providing European long meteorological records, Jurg Luterbacher and Ulf Büntgen for providing their temperature reconstructions. We are also thankful to E. Le Roy Ladurie for the historical evidences he provided to strengthen 
our confidence in the reconstructed extreme warm years. We are undebted to V. Droguet "Conservateur du Musée Château de Fontainebleau", to P. P. Perraud for counselling and guidance during sampling and historical research, to $\mathrm{R}$. Böhm and an anonymous French meteorology amateur for documenting early instrumental records in France. This project was funded by CEA, CNRS (ECLIPSE CAC1000 program) and EC (FP6 ISONET EVK2 CT 2002 00147). This manuscript was improved thanks to the comments of J. Luterbacher and two anonymous reviewers.

Edited by: J. Guiot

\section{References}

Anderson, W. T., Bernasconi, S. M., McKenzie, J. A., Saurer, M., and Schweingruber, F.: Model evaluation for reconstructing the oxygen isotopic composition in precipitation from tree ring cellulose over the last century, Chemical Geology, 182, 121-137, 2002.

Auer, I., Böhm R., Jurkovi, A., Lipa, W., Orlik, A., Potzmann, R., Schöner, W., Ungersböck, M., Matulla, C., Briffa, K., Jones, P., Efthymiadis, D., Brunetti, M., Nanni, T., Maugeri, M., Mercalli, L., Mestre, O., Moisselin, J.-M., Begert, M., MüllerWestermeier, G., Kveton, V., Bochnicek, O., Stastny, P., Lapin, M., Szalai, S., Szentimrey, T., Cegnar, T., Dolinar, M., GajicCapka, M., Zaninovic, K., Majstorovic, Z., and Nieplova, E.: HISTALP - historical instrumental climatological surface time series of the Greater Alpine Region, International Journal of Climatology, 27, 17-4166, 2007.

Baillie, M. G. L. and Pilcher, J. R.: A simple cross-dating program for tree-ring research, Tree-ring Bull., 33, 7-14, 1973.

Barbaroux, C., Bréda, N.: Contrasting seasonal dynamics and distribution of carbohydrate reserves in the stem wood of adult ring porous (sessile oak) and diffuse porous tree (common beech), Tree Physiology, 22, 1201-1210, 2002.

Beniston, M.: The 2003 heat wave in Europe: A shape of things to come? An analysis based on Swiss climatological data and model simulations, Geophysical Research Letters, 31, L02202, doi:10.1029/2003GL018857, 2004.

Bindi, M., Fibbi, L., Maselli, F., and Miglietta, F.: Modelling climate change impacts on grapevine in Tuscany in: Climate Change, Climatic Variability and Agriculture in Europe, edited by: Downing, T. E., Harrison, P. A., Butterfield, R. E., and Lonsdale, K. G., Environmental Change Unit, University of Oxford, UK, 191-216, 2000.

Boettger, T., Haupt, M., Knoller, K., Weise, S. M., Waterhouse, J. S., Rinne, K. T., Loader, N. J., Sonninen, E., Jungner, H., Masson-Delmotte, V., Stievenard, M., Guillemin, M.T., Pierre, M., Pazdur, A., Leuenberger, M., Filot, M., Saurer, M., Reynolds, C.E., Helle, G., and Schleser, G. H.: Wood cellulose preparation methods and mass spectrometric analyses of delta $\mathrm{C}-13$, delta $\mathrm{O}-18$, and nonexchangeable delta $\mathrm{H}-2$ values in cellulose, sugar, and starch: An interlaboratory comparison, Analytical Chemistry, 79, 4603-4612, 2007.

Briffa, K. R.: Annual climate variability in the Holocene: interpreting the message of ancient trees, Quaternary Science Reviews, $19,87,2000$.

Briffa, K. R., Osborn, T. J., Schweingruber, F. H., Harris, I. C., Jones, P. D., Shiyatov, S. G., and Vaganov, E. A.: Low-frequency temperature variations from a Northern tree-ring density network, J. Geophys., 106, 2929-2941, 2001.

Briffa, K. R., Osborn, T. J., Schweingruber, F. H., Jones, P. D., Shiyatov, S. G., and Vaganov, E. A.: Tree-ring width and density data around the Northern Hemisphere: Part 1, local and regional climate signals, The Holocene, 12, 737-757, 2002.

Büntgen, U., Esper, J., Frank, D. C., Nicolussi, K., and Schmidhalter, M: A 1052-year tree-ring proxy for Alpine summer temperatures, Climate Dynamics, 25, 141-153, 2005.

Büntgen, U., Franck, D. C., Nievergelt, D., and Esper, J.: Summer temperature variations in the European Alps, A.D. 755-2004, J. Climate, 19, 5606-5623, 2006.

Chuine, I., Yiou, P., Viovy, N., et al.: Historical phenology: Grape ripening as a climate indicator, Nature, 432, 289-290, 2004.

Danis, P. A., Masson-Delmotte, V., Stievenard, M., Guillemin, M. T., Daux, V., Naveau, P., and Von Grafenstein, U.: Reconstruction of past precipitation $\delta^{18} \mathrm{O}$ using tree-ring cellulose $\delta^{18} \mathrm{O}$ and $\delta^{13} \mathrm{C}$ : A calibration study near Lac d'Annecy, France, Earth Planet. Sci. Lett., 243, 439-448, 2006.

Daux, V., Yiou, P., Le Roy Ladurie, E., Mestre, O., Chevet, J. M., et al.: Temperature and grape harvest dates in France. In: Proceedings of the Global warming, which potential impacts on the vineyards? Dijon, France, 28-30 March 2007, in press.

Dittmar, C., Fricke, W., and Elling, W.: Impact of late frost events on radial growth of common beech (Fagus sylvatica L.) in Southern Germany, European Journal of Forest Research, 125, 249259, 2003.

Esper, J., Cook, E. R., and Schweingruber, F. H.: Low-frequency signals in long tree ring chronologies for reconstructing past temperature variability, Science, 295, 2250-2253, 2002.

Etien, N., Daux, V., Guillemin, M. T., Masson-Delmotte, V., Stievenard, M., Breda, N., Boettger, T., Haupt, M., Mestre, O., and Perraud, P. P.: Summer maximum temperature in northern France over the past century: instrumental data versus multiple proxies (tree-ring isotopes, grape harvest dates and forest fires), Climatic Change, in press.

Frank, D. and Esper, J.: Characterization and climate response patterns of a high-elevation, multi-species tree-ring network in the European Alps, Dendrochronologia, 22, 107-121, 2005.

Frank, D., Büntgen, U., Böhm, R., Maugeri, M., and Esper, J.: Warmer early instrumental measurements versus colder reconstructed temperatures: shooting at a moving target, Quaternary Science Reviews, 26, 3298-3310, 2007.

Garnier, M. : Climatologie de la France - Collections de données statistiques. Mémorial de la Météorologie Nationale, 1967.

Ghil, M.: The SSA-MTM Toolkit: Applications to analysis and prediction of time series, Proc. SPIE, 3165, 216-230, 1997.

Green, J.W.: Wood cellulose, in: Methods in Carbohydrate Chemistry, edited by: Whistler, R. L. and Green, J. W., Academic Press, 9-21, 1963.

Guiot, J., Berger, A. L., Munaut, A. V., and Till, C.: Some new mathematical procedures in dendroclimatology with examples for Switzerland and Morocco, Tree-Ring Bulletin, 42, 33-48, 1983.

Guiot, J., Nicault, A., Rathgeber, C., Edouard, J. L., Guibal, F., Pichard, G., and Till, C.: Last-millennium summer-temperature variations in western Europe based on proxy data, The Holocene, 15, 489-500, 2005.

IPCC: Climate Change 2007: The Physical Science Basis. Con- 
tribution of Working Group I to the Fourth Assessment Report of the Intergovernmental Panel on Climate Change, edited by: Solomon, S., Qin, D., Manning, M., Chen, Z., Marquis, M., Averyt, K. B., Tignor, M., and Miller, H. L., Cambridge University Press, Cambridge, United Kingdom and New York, NY, USA, 996 pp., 2007.

Leavitt, S. W. and Danzer, S. R.: Method for batch processing small wood samples to holocellulose for stable carbon isotope analysis, Analytical Chemistry, 65, 87-89, 1993.

Le Roy Ladurie, E. : Les paysans de Languedoc, Thesis, Ed. intégrale 1966.

Le Roy Ladurie, E., Daux, V., and Luterbacher, J.: Le climat de Bourgogne et d'ailleurs $\mathrm{XIV}^{e}-\mathrm{XX}^{e}$ siècle, Histoire, Economie et Sociétés, 3, 421-436, 2006.

Legrand, J.-P. and Le Goff, M.: Les observations météorologiques de Louis Morin. Météorologie Nationale, Monographie $\mathrm{n}^{\circ} 6$, 1992.

Luterbacher, J., Dietrich, D., Xoplaki, E., Grosjean, M., and Wanner, H.: European seasonal and annual temperature variability, trends and extremes since 1500, Science, 303, 1499-1503, 2004.

Luterbacher, J., Liniger, M. A., Estrella, N., Della-Marta, P. M., Pfister, C., Rutishauser, T., and Xoplaki, E.: The exceptional European warmth of autumn 2006 and winter 2007: Historical context, the underlying dynamics and its phenological impacts, Geophys. Res. Lett., 34, L12704, doi:10.1029/2007GL029951, 2007.

McCarroll, D. and Loader, N. J.: Stable isotopes in tree rings, Quaternary Science Reviews, 23, 771-801, 2004.

Manley, G.: Central England temperatures: monthly-means 1659 to 1973, Quaternary Journal of Royal Met. Society, 100, 389-405, 1974.

Masson-Delmotte, V., Raffalli-Delerce, G., Danis, P. A., Yiou, P., Stievenard, M., Guibal, F., Mestre, O., Bernard, V., Goosse, H., Hoffmann, and Jouzel, J.: Changes in European precipitation seasonality and in drought frequencies revealed by a four century long tree-ring isotopic record from Brittany, western France, Clim. Dynam., 24, 57-69, 2005.

Meier, N., Rutishauser, T., Pfister, C., Wanner, H., and Luterbacher, J.: Grape harvest dates as a proxy for Swiss April to August temperature reconstruction back to A.D. 1480, Geophys. Res. Lett., 34, L20705, doi:10.1029/2007GL031381, 2007.

Moberg, A., Sonechkin, D. M., Holmgren, K., et al.: Highly variable Northern Hemisphere temperatures reconstructed from lowand high-resolution proxy data, Nature, 433, 613-617, 2005.

Moisselin, J. M., Schneider M., Canellas, C., and Mestre, O.: Les changements climatiques en France au XXème siècle, Etude des longues séries homogénéisées de température et de précipitations, La Météorologie, 38, 45-56, 2002.

Paillard, D., Labeyrie, L., and Yiou, P.: Macintosh program performs time-series analysis Eos, Transactions American Geophysical Union, 77, 379-379, 1996.

Parker, D. and Horton, B.: Uncertainties in Central England temperature 1878-2003 and some improvements to the maximum and minimum series, International Journal of Climatology, 25, 1173-1188, 2005.
Pfister, C.: Klimageschichte Schweiz, 1525-1860, Haupt (Ed.), Berne, 1985.

Raffalli-Delerce, G., Masson-Delmotte, V., Dupouey, J. L., Stievenard, M., Breda, N., and Moisselin, J. M.: Reconstruction of summer droughts using tree-ring cellulose isotopes: a calibration study with living oaks from Brittany (western France), Tellus, 56B, 160-174, 2004.

Robertson, J., Waterhouse, J. S., Barker, A. C., Carter, A. H. C., and Switsur, V. R.: Oxygen isotope ratios of oak in east England: implications for reconstructing the isotopic composition of precipitation, Earth Planetary Science letter, 191, 21-31, 2001.

Saurer, M., Schweingruber, F., Vaganov, E. A., Shiyatov, S. G., and Siegwolf, R.: Spatial and temporal oxygen isotope trends at the northern tree-line in Eurasia, Geophys. Res. Lett., 29, 10.1-10.4, 2002.

Schär, C., Vidale P. L, Lüthi, D., Frei, C., Häberli, C., Liniger, M. A., and Appenzeller, C.: The role of increasing temperature variability in European summer heat waves, Nature, 427, 332-336, 2004.

Slonosky, V. C.: Wet winters, dry summers? Three centuries of precipitation data from Paris, Geophys. Res. Lett., 29, 1895, doi:10.1029/2001GL014302, 2002.

Sturm, K., Hoffmann, G., Langmann, B., and Stichler, W.: Simulation of $\delta^{18} \mathrm{O}$ in precipitation by the regional circulation model REMOiso, Hydrological Processes, 19, 3425-3444, 2005.

Treydte, K. S., Schleser, G. H., Helle, G., Frank, D. C., Winiger, M., Haug, G. H., and Esper, J.: The twentieth century was the wettest period in northern Pakistan over the past millennium, Nature, 440, 1179-1182, 2006.

Treydte, K., Frank, D., Esper, J., et al.: Signal strength and climate calibration of a European tree-ring isotope network, Geophys. Res. Lett., 34, L24302, doi:10.1029/2007GL031106, 2007.

Van Engelen, A. F. V. and Geurts. H. A. M.: Historische Weerkundige Waarnemingen, I-III, I: Geschiedenis van weerkundige waarnemingen in het bijzonder in Nederland vóór de prichting van het KNMI, II Vooruitstrevende ideeën over de meteorologie en klimatologie van Petrus van Musschenbroek 1692-1761 IIa: Inleidende tekst bij de meteorologische aarnemingsreeks Utrecht/Leiden 1729-1758, Petrus van Musschenbroek, III: Een rekenmodel dat het verloop van de temperatuur over een etmaal berekent uit drie termijnmetingen van de temperatuur, KNMI publ. 165-I, II, IIa, III (De Bilt. 1983-1992).

Van Leeuwen, C., Trégoat, O., Choné, X., Jaeck, M. E., Rabusseau, S., and Gaudillère, J. P.: Le suivi du régime hydrique de la vigne et son incidence sur la maturation du raisin, Bulletin O.I.V., 76, 367-378, 2003.

Von Grafenstein, U., Erlenkeuser, H., Muller, J., et al.: The cold event 8200 years ago documented in oxygen isotope records of precipitation in Europe and Greenland, Clim. Dynam., 14, 7381, 1998.

Xoplaki, E., Luterbacher, J., Paeth, H., Dietrich, D., Steiner, N., Grosjean, M., and Wanner, H.: European spring and autumn variability and change of extremes over the last half millennium, Geophys. Res. Lett., 32, L15713, doi:10.1029/2005GL023424, 2005. 